\title{
The Survival of Unique Corporate Cultures
}

\author{
Gil S. Epstein
}

Bar-Ilan University, IZA, Bonn and CReAM, London

\section{Renana Lindner Pomerantz}

\author{
Bar-Ilan University
}

\begin{abstract}
In this paper we identify two situations that can lead a firm to hire an executive who supports a corporate culture that differs from the firm's current culture. In the first case, there is similarity between the firm's culture and that of the candidate and in the second case, executives who support the firm's culture constitute a minority of available candidates. In both cases the firm prefers to hire an available candidate, rather than risk a prolonged vacancy. We show how these scenarios can lead to the eradication of unique cultures and to the perpetuation of more common cultures.
\end{abstract}

Keywords: Corporate culture, Organizations, Minority. 


\section{Introduction}

In certain situations, a firm may decide to hire an executive who supports a corporate culture that differs from the firm's current culture. We begin by presenting an example that illustrates such a scenario and provides a glimpse of its potential implications:

In May 2012, Shlomo Yanai resigned after five years as the CEO of Teva Pharmaceutical Industries Ltd. (hereinafter: Teva). He was replaced by Dr. Jeremy Levin, a former senior executive at the global BioPharma company Bristol-Myers Squibb. Only one and a half years later, Dr. Levin had agreed to step down. Analysts suggested that the resignation was a result of his being 'foreigner', lacking familiarity with the Israeli corporate culture. Dr. Levin was replaced by Erez Vigodman, who had served formerly as a CEO of two large Israeli companies. He had no experience with the pharmaceutical industry. Despite his lack of previous familiarity with the pharmaceutical industry, after two years as Teva's CEO, analysts praised his success in reviving Teva from a severe crisis and leading it forward.

In evaluating the case of Teva, which replaced two CEOs in less than two years, analysts established a link between the failure of Dr. Jeremy Levin as Teva's CEO and the fact that he was a foreign CEO in an Israeli company. Erez Vigodman, an Israeli, was hired as Levin's replacement despite his lack of familiarity with the pharmaceutical industry. These observations highlight the fact that the fit between a firm's corporate culture and the culture of its senior executives can have significant consequences for the firm's performance and constitutes a critical factor in executive hiring decisions. The current paper develops a search theoretic model to investigate scenarios in which a firm might choose to hire an executive whose culture diverges from its own, and to examine the broader implications of such hiring decisions. 
The concept of 'corporate culture' was adopted by management scholars around the 1980s. One of the most influential authors in the field was Schein $(1981,1983,1984$, 1985), who built a conceptual framework for analyzing cultures in organizations (Hatch, 1993). A main challenge in the investigation of corporate culture is determining the definition of 'culture'. According to Weber, Shenkar and Raveh (1996), scholars of corporate culture describe the concept as the beliefs and values shared by a company's senior managers with regard to appropriate business practices. The authors distinguish between national and corporate levels of culture and examine the possible roles of both national and corporate cultural fit in post-merger integration processes.

O'Reilly and Chatman (1996) define culture in a similar manner, as 'a system of shared values (that define what is important) and norms that define appropriate attitudes and behaviors for organizational members (how to feel and behave).' According to O'Reilly (1989), a 'strong culture' exists when there is a set of norms and values that are widely shared and strongly held throughout the organization.

Van den Steen (2010) uses an economic model to derive the effects of shared beliefs and values on organization behavior and performance. He finds that firms whose members share beliefs to a greater extent exhibit more delegation, less monitoring, higher utility, higher execution effort, less information collection, less experimentation, faster coordination, fewer influence activities, and less-biased communication. The author suggests that cultural homogeneity within an organization is a pervasive force, because shared beliefs and values reduce differences in objectives that may cause agency problems. Crémer (1993) mentions that shared knowledge enables agents to compute more accurately the benefits and costs of different alternatives, as it provides a means of predicting the reactions of the rest of the organization and evaluating the organization's capacities. 
Our paper is related to the group of papers that link between culture and leadership. To quote Schein (2009): 'culture and leadership are two sides of the same coin and one cannot understand one without the other'. According to the author, when new leaders take over an existing organization, they find an existing culture that is based on the values of previous leaders. The new leader's success may be influenced by his or her level of person-organization fit. Conversely, Van den Steen (2005) shows that, a manager has an important influence on the firm's behavior and performance, not only through his direct actions and decisions but also indirectly. Specifically, a manager with strong managerial beliefs attracts employees with similar beliefs, creating an alignment of beliefs within the firm, which is an important factor in the firm's behavior and performance. In accordance with these papers, our model adopts the basic assumption that alignment between the firm's and its manager's beliefs is advantageous, and that in the absence of such an alignment, the firm's profitability is diminished. Furthermore, in line with Van den Steen (2005), we assume that the manager influences the culture of the firm until, over time, alignment is achieved. However, we do not explicitly assume that this takes place through attraction of employees with similar beliefs. Rather, we adopt the more general assumption that, when a firm hires a manager whose organizational culture differs from its own, an adaptation period ensues, during which the firm experiences a performance penalty, i.e., a temporary reduction in profits. During this adaptation period, the firm and the manager learn how to work together, and the firm adapts its procedures and practices until they match those of the manager, at which point profitability is restored.

The papers cited above, in addition to many others, reflect the strong emphasis in the economic and managerial literature on the importance of homogeneous culture within an organization, and specifically the importance of the congruence between the beliefs 
of the organization and those of its senior employees. However, as in the case of Teva described above, there are numerous real-life cases in which a firm hires a new manager whose culture differs from the firm's - e.g., a CEO from a different country. Such decisions might arise from a desire to quickly appoint a new manager rather than continue the search process in order to find a better firm-manager match.

The current paper deals with such scenarios. Using a search theoretic model ${ }^{1}$, we identify two scenarios in which a firm is likely to hire a manager whose culture differs from its own. The first scenario takes place when the gap between the culture of the firm and the culture of the hired manager is small. In this case, the decision to recruit an executive who is a less-than-perfect match may be more beneficial to the firm compared with a long and exhaustive search for a better fit. In this case, we show that, in the long run, the market converges to an equilibrium that reflects the cultural distribution of executives who were available in the market during the search process.

The second scenario occurs when executives whose corporate culture matches that of the firm constitute a minority within the group of suitable candidates. Under this scenario, the firm prefers to compromise and hire an available candidate, even one whose culture differs from that of the firm, rather than take the risk of remaining with

\footnotetext{
${ }^{1}$ The version of the search model that we adopt is widely used in the economic literature about search in the marriage market in general and in papers that examine the willingness of people to marry partners whose cultures differ from their own (e.g., a marriage between a local and an immigrant) in particular. An interesting link exists between these papers and our current paper. A key assumption in papers about search in the marriage market is that people prefer similarity in marriage. This is in line with the managerial literature's emphasis on homogenous culture, discussed above. However, there are also papers that show significant advantages in marriages between people who differ from each other in their religions, cultures, etc. For example, Furtado and Theodoropoulos $(2009,2010)$ show that intermarriage increases an immigrant's employment probability by approximately 4\%. Epstein and Lindner Pomerantz (2013) show that immigrants prefer marrying natives when the immigrants are a small minority in the population, such that the likelihood of meeting and marrying a fellow immigrant is low.
} 
a vacancy for a long period. In this case, we show that in the long-run, the process is expected to eradicate small and unique cultures and to perpetuate more prevalent corporate cultures.

Combining both scenarios, our paper actually shows that a minority culture is difficult to maintain, especially when that culture is not so different from the majority culture.

Our paper contributes to the literature on corporate culture, both by showing the different incentives that induce firms to change their corporate cultures even when there is no apparent urgency to do so, and by showing how changes of corporate cultures can lead to the disappearance of small and unique cultures and to the perpetuation of more common cultures.

The paper continues as follows: In the next section we present the model, and in section 3 we analyze the model's three potential equilibria. In section 4 we discuss the longterm market implications of the results of our analysis, and section 5 concludes.

\section{The Model}

Assume a countably infinite number of firms that are seeking to recruit senior employees (e.g., CEOs, Vice Presidents, etc.). Firms are continuously looking for suitable candidates for different positions. Assume also a countably infinite number of candidates that apply for the positions. They apply given a Poisson process. A fraction $p$ of firms has a corporate culture of type $a$, and a fraction $(1-p)$ has a corporate culture of type $b$. Correspondingly, a fraction $q$ of candidates believes in corporate 
culture type $a$ and the complementary fraction $(1-q)$ believes in corporate culture type b. For simplicity, we assume that $q>1-q$.

Each firm in the group of hiring firms has a vacant executive position and is interested in filling that position by recruiting a candidate from the pool of available candidates. We assume that the candidates differ only in their attitudes regarding corporate culture, which can be from type $a$ or type $b$, and that they cannot change their types. When faced with a candidate, each firm acts according to the following strategy: in the case where the candidate believes in the same corporate culture as the firm, the firm recruits the candidate and a job contract is signed. In the case where the candidate believes in the other corporate culture, the firm has two options:

i. The firm can decide not to sign an agreement with the candidate and continue to wait until a candidate who believes in the same corporate culture submits his candidacy. Until the position is filled, the firm's profit is zero.

ii. The firm can sign a contract with the candidate. In this case, we assume that there is an adaptation period, during which the firm and the senior employee learn how to work together despite their divergent cultures. During this period, the corporate culture of the firm gradually evolves into the culture of the new senior employee (e.g., the firm's pre-existing procedures and practices are adjusted to match the culture of the new manager, and so on). At the end of the adaptation period, the firm and the senior employee have the same corporate culture. In this case, we assume that, during the adaptation period, the firm's profit rate is lower than it would have been if the firm had hired someone with a culture matching its own. 
Specifically, we assume that if a firm recruits a senior employee whose corporate culture is the same as that of the firm, the firm obtains a profit rate of $\pi$. However, a firm that recruits someone whose culture differs from its own obtains a lower profit rate during the adaptation period. This profit rate gradually increases over the course of the adaptation period (as the firm's corporate culture evolves), and at the end of the adaptation period when the culture of the firm and the culture of the senior employee are the same, the profit rate converges to its maximal value of $\pi$.

We assume that when the firm decides to sign an agreement with a specific candidate, it offers the candidate his reservation wage, meaning that the candidate always accepts the job offer.

Formally, we assume that upon signing an agreement with a candidate, a firm gains the following profit rate:

$$
\Pi_{x}=\pi\left(1-e^{-t / \tau(x, y)}\right)
$$

Where:

- $x \in\{a, b\}$ - represents the corporate culture of the firm.

- $y \in\{a, b\}$ - represents the corporate culture of the senior employee.

- $\quad t$ represents the time elapsed since the point at which the agreement was signed.

- $\quad \tau=\tau(x, y)$ is a function that satisfies:

$$
\left\{\begin{array}{l}
\tau(x, y)=0 \quad \text { if } \quad x=y \\
\tau(x, y)>0 \quad \text { if } \quad x \neq y
\end{array}\right.
$$


We refer to $\tau(x, y)$ as a measure of the initial differences between the cultures of the firm and the senior employee. If the firm and the senior employee both initially share the same culture, the value of the measure is zero, and we can see in equation (1) that the profit rate of the firm is $\pi$. However, if the cultures differ, the value of the measure is positive, which means that the firm temporarily suffers from a reduction in its profits. In this case the profit rate converges to $\pi$ only at time infinity (or practically when $t$ is high enough). We also assume that as the differences between the cultures of the firm and the senior employee are greater, $\tau(x, y)$ increases. Thus, larger differences yield a longer adaptation period.

In the case that the candidate and the firm share the same culture, a job contract is signed. The reason for this is when both share the same culture, profits are maximized at a rate of $\pi$. However, when the firm faces a candidate who has a different culture, the firm has to decide whether to recruit him or continue the search process for an appropriate candidate. We assume that when making its decisions regarding the recruitment, the firm considers a profits over a given time horizon of $T$. Given this time horizon, the firm calculates its profits over the different options.

1. If the firm recruits the candidate, the overall profit gained during this time frame is equal to:

(2) $\int_{0}^{T} \pi\left(1-e^{-t / \tau(x, y)}\right) e^{-\lambda t} d t$

where $\lambda$ is the discount rate.

2. If the firm decides to remain with a vacancy and continue the search process, its profit is zero until a candidate with a matching culture is identified. In this case, the firm evaluates its expected profits, based on the probability to meet a candidate who shares the same culture in the future. These expected profits are: 
(3) $\int_{0}^{T} \alpha \cdot w \cdot \pi \cdot e^{-\lambda t} d t$

where $\alpha$ represents the probability to meet candidates who arrive given a Poisson process; and $w$ represents the proportion of candidates who share the same culture as the firm (i.e., $w=q$ for a type $a$ firm, and $w=1-q$ for a type $b$ firm).

There is a critical value $w=w^{*}$ for which the firm is indifferent between recruiting the candidate or remaining with a vacancy (equation 2 equals equation 3 ):

(4) $\int_{0}^{T} \pi\left(1-e^{-t / \tau(x, y)}\right) e^{-\lambda t} d t=\int_{0}^{T} \alpha \cdot w \cdot \pi \cdot e^{-\lambda t} d t$

Solving (4) we obtain that $w^{*}$ equals:

(5) $w^{*}=\frac{1}{\alpha}\left[1+\lambda \tau\left(\exp \left(-T\left(\lambda+\frac{1}{\tau}\right)\right)-1\right) /(\lambda \tau+1)(1-\exp (-\lambda T))\right] .^{2}$

\section{Proposition 1:}

A firm prefers to remain with a vacancy rather than to recruit a candidate who believes in a different culture if and only if $w>w^{*}$.

When the firm knows that there is a sufficiently high proportion of candidates whose corporate culture matches that of the firm, it rejects opportunities to sign agreements with candidates holding different attitudes and prefers to wait for future opportunities to make an agreement with a candidate whose culture matches its own. However, when the number of candidates who share the firm's beliefs is below this threshold, the firm

\footnotetext{
${ }^{2}$ Proof will be provided upon request.
} 
avoids the risk of remaining with a vacancy and prefers recruiting candidates with different attitudes.

\section{Proposition 2:}

The probability that a firm will end up signing an agreement with a senior employee who does not share the same culture as the firm increases with the discount rate $\lambda$ and decreases with: (i) the probability to meet candidates who arrive according to a Poisson process, $\alpha$; (ii) the differences between the cultures of the firm and the senior employee, $\tau(x, y)$.

When the discount factor, increases, the firm's preference for the present over the future increases. That is, the firm prefers to compromise rather than wait for someone else, and recruits its current candidate. However, when the arrival rate of candidates increases, the firm prefers to wait and continue the search process. This is also the case when the difference between the corporate cultures increases.

\section{Equilibrium}

As described above, when meeting a candidate who does not share the same culture as the firm, the firm has to decide whether to remain with the vacancy, hoping to meet an appropriate candidate in the future, or to sign an agreement with the current candidate. Hereinafter we will refer to firms that make the first type of decision as "selective", and to firms that make the second type of decision as "unselective". Equilibrium exists when a selective firm cannot benefit from becoming unselective, and vice versa.

According to Proposition 1, we have three possible types of equilibria in the market: 
A. If $q<w^{*}$ (which also means that $1-q<w^{*}$ ), then both types of firms- $a$ and $b$-are unselective. When this is the case, each firm recruits the first candidate it meets. We refer to this kind of equilibrium as a Pooling Equilibrium.

B. If $1-q>w^{*}$ (which also means that $q>w^{*}$ ), then both types of firms are selective. When this is the case, type $a$ firms recruit only senior employees of type $a$, and type $b$ firms recruit only senior employees of type $b$. We refer to this kind of equilibrium as a Segregating Equilibrium.

C. If $1-q \leq w^{*} \leq q$, then type $a$ firms are selective, whereas type $b$ firms are unselective. We refer to this kind of equilibrium as Semi-Segregating Equilibrium.

One can see that the analysis presented so far yields the following corollary:

\section{Corollary 1:}

a. A small enough gap between corporate cultures a and $\mathrm{b}$ results in the Pooling Equilibrium.

b. A large enough gap between corporate cultures a and $\mathrm{b}$ results in the Segregating Equilibrium.

The first part of the corollary deals with a situation in which there is almost no difference between the two types of corporate cultures. When this is the case, a given firm prefers to recruit the current candidate rather than continue the search process, although this might entail a change in the firm's corporate culture. 
Regarding the second part of the corollary, when there is a substantial difference between the two cultures, the firms prefer to remain with a vacancy, although this decision prolongs the search process.

Figure 1 illustrates the negative relationship between the critical value $w^{*}$ and the measure of the differences between the cultures of the firm and the candidate, $\tau$. We use the figure to demonstrate the three possible equilibria, under the assumption that $q=0.8$. The dashed lines in the figure represent $q$ and $l-q$.

\section{FIGURE 1 HERE}

As one can see, the graph can be divided into three areas corresponding to the three types of equilibria. For $w^{*}>q$ the Pooling Equilibrium holds; for $w^{*}<1-q$ the Segregating Equilibrium holds; and for $1-q \leq w^{*} \leq q$ the Semi-Segregating Equilibrium holds. If we were to assume a higher value of $q$, the middle area would be wider, meaning that the probability of obtaining the Semi-Segregating Equilibrium would increase. This would happen because an increase in the proportion of type $a$ candidates (and a corresponding decrease in the proportion of type $b$ candidates) strengthens the incentive of type $a$ firms to be selective and the incentive of type $b$ firms to be unselective. On the other hand, as the value of $q$ decreases and approaches 0.5 (reflecting a case in which the population is more balanced), the scope of the SemiSegregating Equilibrium decreases, and the scopes of the Pooling and the Segregating Equilibria increase. For such values of $q$, we would expect to obtain the Pooling Equilibrium for small gaps between the cultures and the Segregating Equilibrium for large gaps between the cultures. 


\section{Discussion: The Survival of Unique Corporate Cultures}

In the model presented above we sought to investigate what might cause a firm to hire an executive with a different corporate culture.

Our analysis points to two possible situations that induce firms to change their corporate cultures, even at the cost of lowering their profitability. The first occurs when the gap between the corporate culture of the hiring firm and the culture of the prospective candidate is small. In this case, recruiting an executive whose culture does not match the firm's is more beneficial to the firm than continuation of the search process. In our model, this translates into a case in which both type $a$ firms and type $b$ firms are unselective, and the Pooling Equilibrium takes place.

The second situation that supplies an incentive for a firm to change its corporate culture is when executives whose culture matches that of the hiring firm constitute a minority in the group of suitable candidates. Under this scenario, the firm prefers to compromise and to hire an available candidate with a different culture rather than to risk remaining with a vacancy for a long time. In contrast, a hiring firm whose culture matches that of the majority of candidates can afford to remain selective. This is actually the description of the Semi-Segregating Equilibrium.

These results have interesting long-run implications regarding the extent to which different types of corporate cultures can thrive in the market. Let us return to the structure of the market of firms under the assumptions we adopted in our model. We assumed that in the initial situation, a fraction $p$ of the firms are of type $a$ and that a fraction $(1-p)$ of firms are of type $b$. This division remains constant under the Segregating Equilibrium, in which both firms are selective and remain loyal to their 
current corporate cultures. However, the division of the firms changes if either the Pooling Equilibrium or the Semi-Segregating Equilibrium takes place.

As discussed above, the Pooling Equilibrium takes place when the gap between the two cultures is sufficiently small. In this equilibrium each firm recruits the first candidate it meets, and this candidate can be from type $a$ with probability $q$ and from type $b$ with probability $(1-q)$. Hence, the distribution of the firms changes towards the candidates' distribution, and the proportions of firms holding corporate cultures of types $a$ and $b$ are $q$ and $(1-q)$, accordingly. This means that the market converges to an equilibrium that reflects the cultural distribution of the executives who were available in the market during the search process.

The Semi-Segregating Equilibrium scenario also yields a firm culture distribution that differs from the initial one. In this case, firms of type $a$ are selective and recruit only type $a$ candidates; however, firms of type $b$ are unselective and recruit the first candidates they meet. This means that over the time, there are firms of type $b$ that recruit type $a$ executives and change their corporate culture. Thus, the proportion of type $a$ firms increases, and the proportion of type $b$ firms decreases. In the long run, this process is expected to eradicate type $b$ firms and to homogenize the firms to type $a$ only.

In order to illustrate the three types of equilibria, we now present a simulation of the search process. For simulation purposes only, we simplify the representation by assuming that if the firm hires the candidate, culture changes immediately and not gradually (as in reality). This simplifies our simulation but does not affect the firm's decision process and corresponding market equilibrium. 
We assume that at the beginning of the search process, $60 \%$ and $80 \%$ of the firms and candidates, respectively, are of type $a$. We run the simulation three times, with three different values of $\tau$, which, as stated, represents the cultural gap between firms $a$ and $b$. Consequently, we receive three different values of the critical value $w^{*}$. At each iteration of the simulation, a random firm meets a random candidate. If the candidate shares the same culture as the firm, a job contract is signed and the firm does not change its type. However, in cases in which the candidate's culture is different from that of the firm, we calculate the values of equations (2) and (3), which, as described above, represent the profits of the firm with and without hiring the candidate. Based on these calculations, the firm decides whether it hires the candidate or not. After each iteration, we recalculate the distribution of the firms between types $a$ and $b$, and present the distribution as a function of the iteration number (which is equivalent to time). Figure 2 presents the results of our simulation:

\section{FIGURE 2 HERE}

- Assuming a small gap between cultures $a$ and $b(\tau=0.3)$ yields the Pooling Equilibrium, meaning that every meeting between a firm and a candidate results in an agreement. Figure 2 a shows that, after a while, the distribution of the firms approaches the distribution of the candidates.

- Assuming a medium gap between cultures $a$ and $b(\tau=2)$ yields the SemiSegregating Equilibrium, meaning that type $a$ firms hire only type $a$ candidates, where type $b$ firms hire any candidate they meet. Figure $2 \mathrm{~b}$ shows that, after a while, type $b$ firms become extinct, and the market consists of type $a$ firms only.

- Assuming a large gap between cultures $a$ and $b(\tau=6)$ yields the Segregating Equilibrium, meaning that an agreement is signed only when the firm and the 
candidate share the same culture. Figure $2 \mathrm{c}$ shows that the distribution of the firms does not change over time.

The result of the situation we have just described is the disappearance in the long run of firms with unique corporate cultures. Consider, for example, a family-run coffee shop with unique characteristics that distinguish it from larger and more commercial coffee shops. Assume that, until now, the coffee shop has been managed by family members, but suitable family members are no longer available to manage the shop, and the family has to find a new manager. Since the family knows that there are only a few potential managers who believe in its unique characteristics, and many more who believe in the corporate culture of larger and more commercial coffee shops, the family prefers to recruit a candidate from the majority group instead of waiting until it finds a suitable manager from the minority group. It is reasonable to assume that numerous family businesses find themselves in such situations. This suggests that in the long run, the corporate culture of larger businesses is expected to take over that of smaller businesses, which can be expected to disappear.

Another interesting example is presented in the following scenario: Imagine a situation in which there are many firms that believe in corporate culture type $a$, but then a large new business school is founded that educates its students according to corporate culture type $b$. After a while, the graduates of this school start to work as managers of firms. If this school is large enough, after a few seasons type $b$ managers become the majority of the suitable candidates for the management of firms, and type $a$ managers are the minority. This means that type $a$ firms find it difficult to recruit type $a$ managers, and some of them prefer to compromise and hire type $b$ managers. After a while, type $b$ corporate culture takes over type $a$, which is expected to disappear in the long run. 


\section{Concluding Remarks}

This paper shows that a minority organizational culture is difficult to maintain, especially when that culture is not so different from the majority culture. More specifically, we identify situations in which a firm might choose to recruit an executive whose corporate culture is different from the firm's, thereby changing its corporate culture. A firm might make such a decision when its culture is sufficiently similar to the culture of the prospective hire to make it more beneficial to hire the executiveeven if he is not a perfect match - than to prolong the search process to find such a match. In addition, when a firm has a "unique" culture, supported by only a minority of candidates, it is more likely to prefer to compromise and to hire an executive from the majority group rather than to sustain a prolonged vacancy. After a while, this situation is expected to lead to the disappearance of small and unique cultures in favor of more prevalent ones. 


\section{References}

Crémer J. 1993. Corporate culture and shared knowledge. Industrial and Corporate Change 2 (3): 351-386.

Epstein GS. 2012 Employer's Information and Promotion-Seeking Activities Economics and Business Letters, 1(4), 21-32,.

Epstein GS, Lindner-Pomerantz R. 2013. Assimilation through marriage. Review of International Economics 21 (2): 191-203.

Furtado D, Theodoropoulos, N. 2009. I'll Marry You if You Get Me a Job: Marital Assimilation and Immigrant Employment Rates. International Journal of Manpower 30: 116-126.

Furtado, D, Theodoropoulos, N. 2010. Why Does Intermarriage Increase Immigrant Employment? The Role of Networks. Journal of Economic Analysis and Policy 10 (1): Article 101.

Hatch MJ. 1993. The dynamics of organizational culture. The Academy of Management Review 18 (4): 657-693.

O'Reilly CA. 1989. Corporations, culture and commitment: Motivation and social control in organizations. California Management Review 31: 9-25.

O'Reilly CA, Chatman JA. 1996. Culture as social control: Corporations, culture and commitment. Research in Organizational Behavior 18: 157-200.

Schein EH. 1981. Does Japanese management style have a message for American managers? Sloan Management Review 23 (1): 55-68.

Schein EH. 1983. The role of the founder in creating organizational culture. Organizational Dynamics 12 (1): 13-28.

Schein EH. 1984. Coming to a new awareness of organizational culture. Sloan Management Review 25 (2): 3-16.

Schein EH. 1985. Organizational Culture and Leadership, Jossey-Bass: San Francisco, CA.

Schein, EH. 2009. The Corporate Culture Survival Guide, Jossey-Bass: San Francisco, CA.

Van den Steen, E. 2005. Organizational beliefs and managerial vision. Journal of Law, Economics and Organization 21 (1): 256-283.

Van den Steen, E. 2010. Culture clash: The costs and benefits of homogeneity. Management Science 56 (10): 1718-1738.

Weber Y, Shenkar O, Raveh A. 1996. National and corporate cultural fit in mergers/acquisitions: An exploratory study. Management Science 42 (8): 1215-1227. 
Figure 1

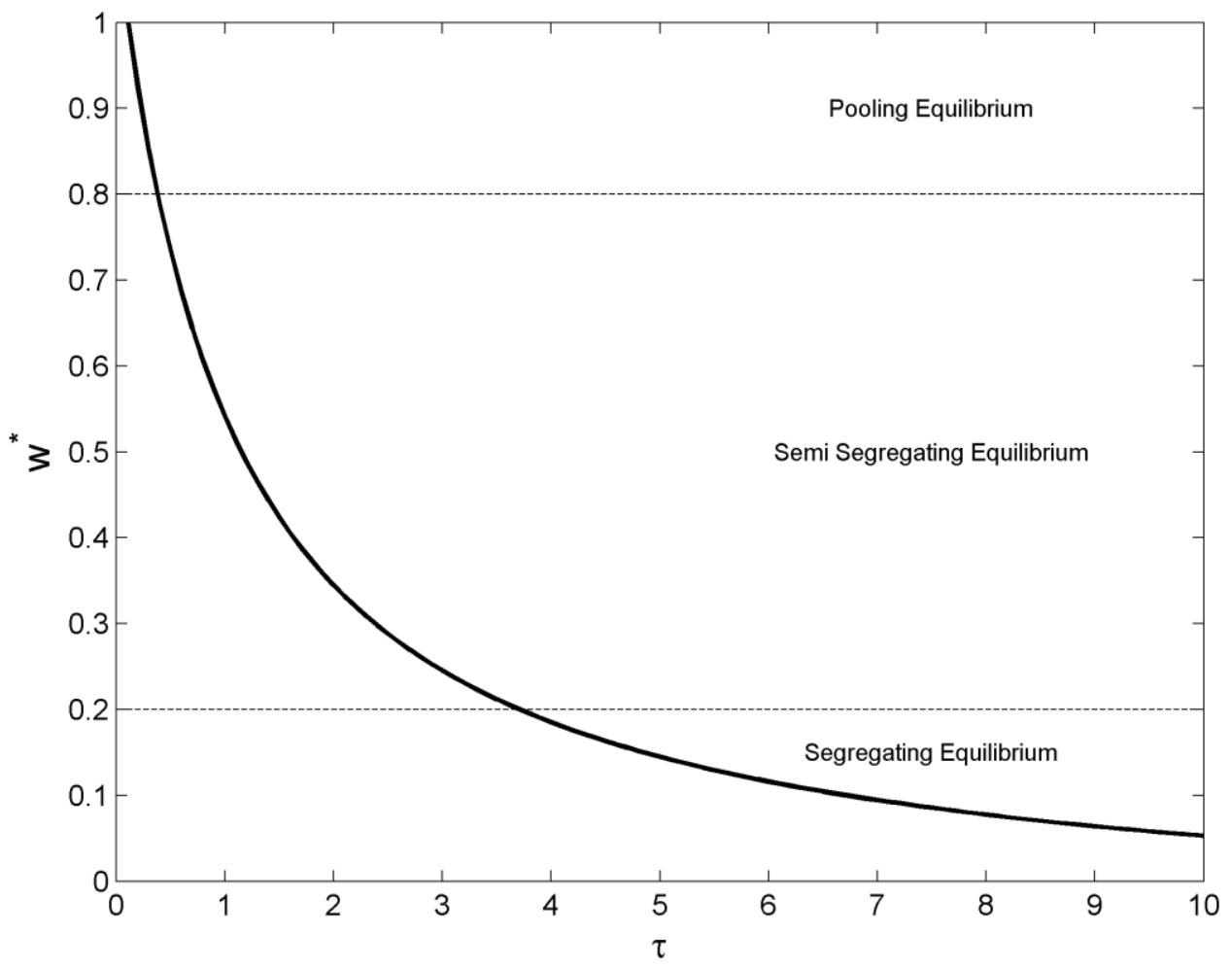

Figure 2
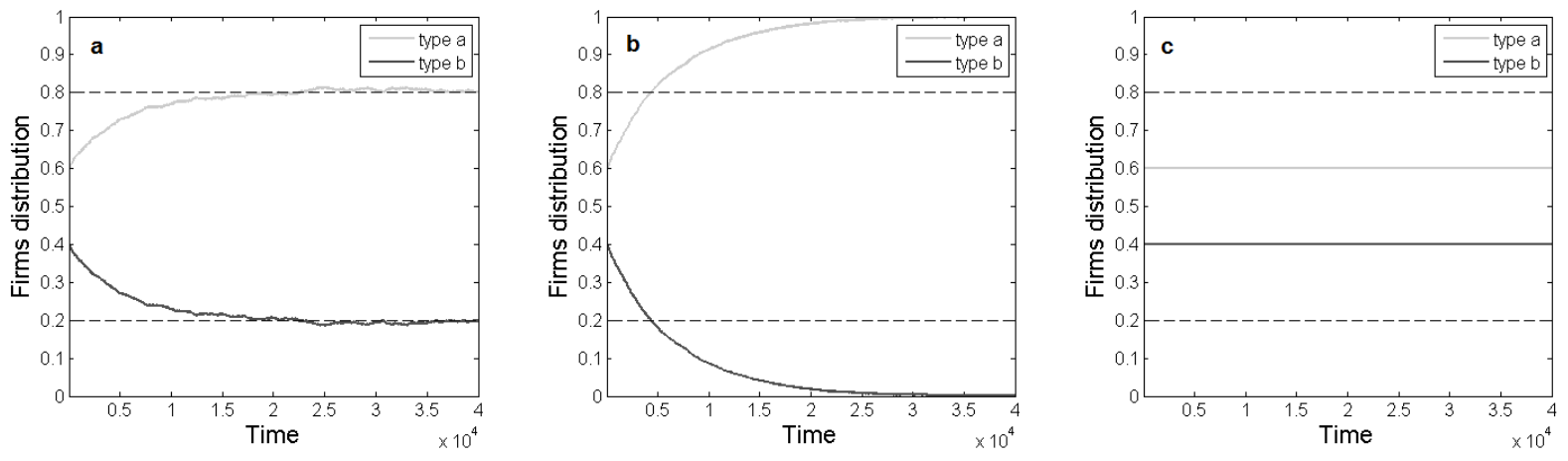